\section{Cuff leak tests: analysis of diagnostic accuracy in observational cohorts of patients with acute respiratory failure}

\author{
Diana Guerra, Zachary Mulkey, \\ Kenneth Nugent
}

Department of Internal Medicine,Texas Tech University Health Sciences Center, Lubbock, TX, USA

\begin{abstract}
Cuff leak tests provide clinicians with information about upper airway narrowing and may help predict weaning success. However, most clinical trials reporting this measurement are small, and the utility of this test remains uncertain. We identified all clinical studies using cuff leak tests in the PubMed, Google Scholar, EMBASE, and Cochrane Central Register of Controlled Trials databases using multiple search terms, including cuff leak test, laryngeal edema, extubation, and stridor, and abstracted quantitative information on cuff leaks and outcomes (stridor and reintubation). We reviewed six studies which included 958 patients with acute respiratory failure in intensive care units. Eighty-two patients (8.5\%) had postextubation stridor. The weighted mean cuff leak was $119( \pm 51)$ mls in the patients with stridor and $313( \pm 24) \mathrm{mls}$ in patients without stridor $(\mathrm{P}<0.01)$. Sixty-six patients required reintubation. The presence of stridor had a sensitivity of 0.60 (95\% CI 0.48-0.72), a specificity of 0.96 (95\% CI 0.94-0.97), and a positive likelihood ratio of 13.4 (95\% CI 6.9-25.7) for predicting reintubation. No single clinical parameter consistently predicted stridor. Patients with postextubation stridor have smaller cuff leak volumes than patients who do not have stridor and are more likely to require reintubation. Cuff leak measurements can improve decision making with extubation protocols.
\end{abstract}

\section{Introduction}

Evidence-based guidelines published in 2001 recommended that the removal of an artificial airway should be based on assessment of airway patency and the ability of the patient to protect the airway but scored this recommendation a Grade C (expert opinion). ${ }^{1}$ Extubation failure requiring reintubation has significant morbidity and mortality related to both the reintubation itself and the complications sec- ondary to prolonged mechanical ventilation. Some authors have reported that the mortality in patients requiring reintubation can be as high as $40 \%$. Most patients requiring early reintubation have either laryngeal edema or laryngospasm and develop stridor after extubation; this occurs in 2 to $38 \%$ of intubated intensive care unit (ICU) patients. ${ }^{2-11}$ The endotracheal tube (ETT) cuff leak test has been studied as a predictor test for postextubation stridor (PES). This relatively simple, noninvasive method to identify upper airway edema was initially described in children using the presence or absence of an air leak with the cuff on the endotracheal tube deflated as a prognostic indicator of PES. ${ }^{12}$ Miller and Cole reported better accuracy by quantifying the air leak. ${ }^{2}$ Most clinical trials reporting this measurement are small and non-randomized. The literature includes contradictory results, and the utility of this test remains uncertain. These differences in results reflect the multiple variables involved in these studies, including the patient population, care setting (ICU vs. postoperative care unit), length of mechanical ventilation, methods used to determine the cuff leak volume, and the cut-off for an abnormal cuff leak volume.

Our goals were to identify clinical trials of adults with acute respiratory failure and analyze information using meta-analysis methods for test accuracy to answer the following questions: Do cuff leak tests provide valuable information about upper airway narrowing in patients in ICUs recovering from acute respiratory failure? Do the cuff leak tests predict postextubation stridor and/or reintubation?

\section{Materials and Methods}

\section{Literature search and data sources}

We searched the PubMed database to identify all clinical studies on cuff leak tests done in ICU patients. We used the following search terms laryngeal edema (MeSH term), cuff leak test (text word), extubation (text word), postextubation (text word), stridor (text word), and combinations of these terms using an AND in the search query. Limits were set for human only, adults (19+ years), and English language. Seven separate searches were done, and the lists were combined for review (Figure 1). The PubMed related articles algorithm was used, and the reference lists from articles selected for full text review were also reviewed carefully for additional articles. We also searched Google Scholar, EMBASE, and Cochrane Central Register of Controlled Trials databases, but did not identify any additional articles. We analyzed all the articles that met the following inclusion criteria: i) Population: adult patients in ICU with acute respiratory
Correspondence: Kenneth Nugent, Department of Internal Medicine, Texas Tech University Health Sciences Center, Lubbock, TX, USA. Tel. + 1.806.743.3155 - Fax: +1.806.743.3148.

E-mail: kenneth.nugent@ttuhsc.edu

Key words: extubation, reintubation, cuff leak test, mechanical ventilation, stridor, laryngeal edema.

Conflicts of interests: the authors have no potential conflicts of interests.

Received for publication: 30 0ctober 2011

Revision received: 1 January 2012.

Accepted for publication: 12 January 2012.

This work is licensed under a Creative Commons Attribution NonCommercial 3.0 License (CC BYNC 3.0).

CCopyright D. Guerra et al., 2012

Licensee PAGEPress, Italy

Chest Disease Reports 2012; 2:e3

doi:10.4081/cdr.2012.e3

failure. We eliminated articles reporting cases with complex airway problems and patients who were extubated after short intervals following surgery. ${ }^{6,8} \mathrm{ii}$ ) Intervention: cuff leak test performed before extubation with quantitative information (absolute leak volume or leak volume expressed as \% tidal volume). We eliminated articles reporting audible cuff leaks. ${ }^{3,6,13,14}$ iii) Outcomes: successful extubation, reintubation, or stridor. iv) Study design: randomized and non-randomized clinical trials. Exclusion criteria included pediatric patients (children $<18$ years) and immediately postoperative patients. ${ }^{8}$ This literature search was completed January 20, 2011, and updated between December 14 and December 18, 2011, during a revision of the manuscript.

\section{Quality of the evidence}

Abstracts were reviewed to identify studies for additional analysis. Six studies were selected for critical appraisal. The authors' names and affiliations were removed from the articles, and data were retrieved by two reviewers (DG, KN) using a structured review form. We extracted information on publication year, patient setting, number of patients and/or extubations, age, gender, inclusion criteria, length of mechanical ventilation, primary outcome, recommendations for optimal cuff leak cut-off value, and methods for cuff leak measurements. Both reviewers then met and compiled a final table of information; disagreements were resolved by discussion. One reviewer (DG) also evaluated the articles for quality using the MINORS (Methodological Index For NonRandomized Studies) criteria:;5-18 two reviewers (DG, KN) discussed these assignments 
after the initial review. We chose this scoring system for assessing the quality of the data of the nonrandomized clinical trials since it is easy to apply and has good reliability, consistency, and correlation with other scoring systems. It uses a score from 0 to 2 if the criterion is reported or not and if it is adequate or not. The maximal score is 24 (12 items) for comparative studies and 16 (8 items) for noncomparative studies. ${ }^{15}$ All studies reported the method for identifying stridor (an audible high pitched inspiratory wheeze requiring medical intervention and often associated with respiratory distress). All studies reported the details for measuring the cuff leak using the method described by Miller and Cole. ${ }^{2}$ This method compares the average exhaled volume with the endotracheal tube cuff inflated and then deflated to calculate an absolute leak volume and a percent leak volume.

\section{Analysis}

We used the Meta-DiSc software program to calculate pooled values for sensitivity, specificity, positive and negative likelihood ratios, and diagnostic odds ratio. ${ }^{19}$ This software was developed to perform meta-analysis of the accuracy of diagnostic tests and calculates weighted mean values with $95 \%$ confidence intervals (95\% CI). Heterogeneity among studies is estimated using the $\mathrm{I}^{2}$ test in which low $P$ values suggest more heterogeneity than expected by chance. Numbers with parentheses in the text and the tables represent the mean \pm 1 standard deviation.

\section{Results}

\section{Study characteristics}

Our searches identified 195 articles possibly relevant to the primary study questions (Figure 1). Seventy-three abstracts and 18 full texts were reviewed; six articles were selected for data abstraction. . $^{2,5,7,7,9,10}$ These six studies were published between 1992 and 2007; all were non-randomized clinical trials using observational cohorts (Table 1). All the studies were done in ICUs, including two medical ICUs, one in a combined medical ICU and surgical ICU, two unspecified ICUs, and one trauma ICU. The studies included 958 adult patients with 970 extubations. The patient population included 498 men with extubations and 396 women with extubations with an average age of 63 years. One study did not report ages, and one did not report gender dis-
195 publications identified through 7 separate electronic database searches using PubMed

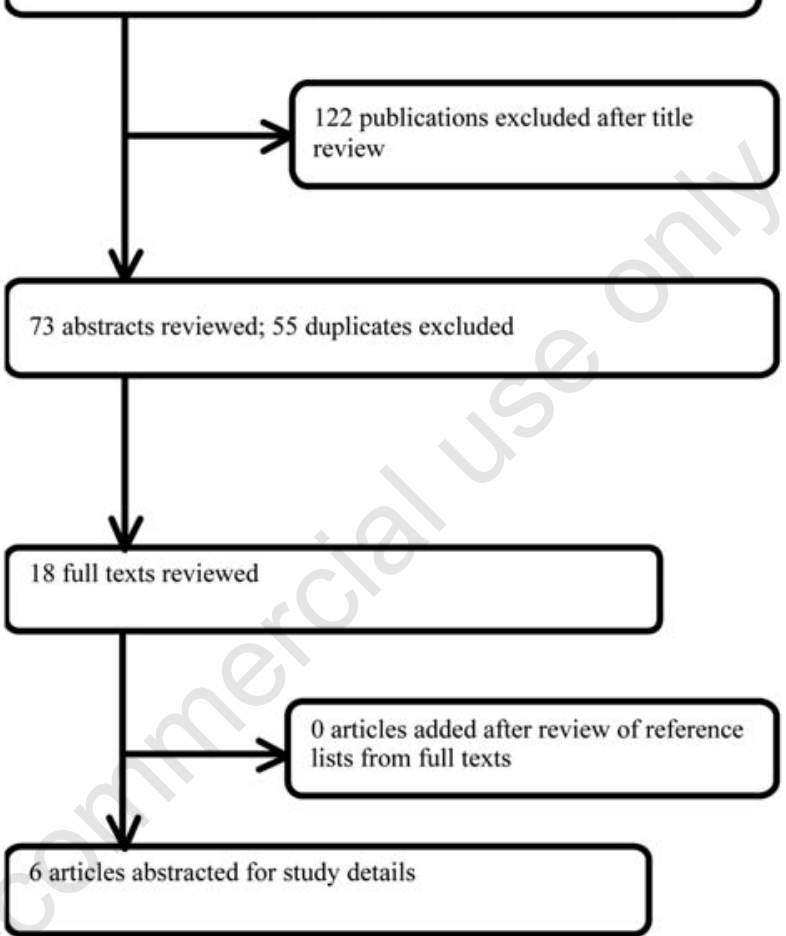

Figure 1. Electronic search strategy.

Table 1. Study characteristics.

\begin{tabular}{|c|c|c|c|c|c|c|c|c|c|}
\hline $\begin{array}{l}\text { Study } \\
\text { (ref.) }\end{array}$ & Year & $\begin{array}{l}\text { Study } \\
\text { type }\end{array}$ & Setting & $\begin{array}{l}\text { Patients/ } \\
\text { extubations }\end{array}$ & Age & $\begin{array}{l}\text { Male/ } \\
\text { female }\end{array}$ & Inclusion criteria & $\begin{array}{c}\text { Mechanical } \\
\text { ventilation length }\end{array}$ & $\begin{array}{l}\text { Main } \\
\text { outcome }\end{array}$ \\
\hline Miller $^{2}$ & 1996 & $\begin{array}{l}\text { Observational } \\
\text { cohort }\end{array}$ & MICU & $88 / 100$ & $63 \pm 17^{\$}$ & $42 / 58^{*}$ & $\begin{array}{l}\text { Patients admitted to } \\
\text { MICU and intubated for } \\
\text { at least } 24 \text { hours }\end{array}$ & $5.8 \pm 0.5 \mathrm{~d}^{\$}$ & Stridor \\
\hline Jaber $^{4}$ & 2003 & $\begin{array}{c}\text { Observational } \\
\text { cohort }\end{array}$ & ICU & 112 & $61 \pm 19$ & $78 / 34$ & $\begin{array}{l}\text { All patients admitted to } \\
\text { ICU with planned extubation }\end{array}$ & $\begin{array}{c}5.5 \pm 6.3 \mathrm{~d}(\mathrm{NoS})^{\#} \\
10.9 \pm 7.0 \mathrm{~d}(\mathrm{~S})^{\S}\end{array}$ & Stridor \\
\hline Sandhu $^{5}$ & 2000 & $\begin{array}{c}\text { Observational } \\
\text { cohort }\end{array}$ & Trauma ICU & 110 & $\mathrm{NR}^{\circ}$ & $80 / 30$ & $\begin{array}{l}\text { All trauma patients who } \\
\text { required intubation }\end{array}$ & $>24 \mathrm{~h}$ & Stridor \\
\hline Kriner $^{6}$ & 2005 & $\begin{array}{c}\text { Observational } \\
\text { cohort }\end{array}$ & MICU and SICU & 462 & $61 \pm 17$ & $246 / 216$ & $\begin{array}{l}\text { All patients who } \\
\text { required intubation }\end{array}$ & $\begin{array}{c}4.5 \pm 4 \mathrm{~d}(\mathrm{NoS})^{\#} \\
6.5 \pm 4 \mathrm{~d}(\mathrm{~S})^{\S}\end{array}$ & Stridor \\
\hline Wang $^{9}$ & 2007 & $\begin{array}{l}\text { Observational } \\
\text { cohort }\end{array}$ & MICU & 110 & $71 \pm 13$ & $52 / 58$ & $\begin{array}{l}\text { All patients admitted to } \\
\text { ICU requiring intubation } \\
\text { and had planned extubation }\end{array}$ & $13 \pm 14 \mathrm{~d}$ & Stridor \\
\hline De Bast ${ }^{10}$ & 2002 & $\begin{array}{l}\text { Observational } \\
\text { cohort }\end{array}$ & ICU & 76 & $67(51-76)$ & $\mathrm{NR}^{\circ}$ & $\begin{array}{c}\text { All adult patients ( }>18 \text { years) } \\
\text { who had been intubated for at } \\
\text { least } 12 \text { hours and were about } \\
\text { to be extubated }\end{array}$ & $\begin{array}{l}<2 \text { days }(50 \%) \\
>2 \text { days }(50 \%)\end{array}$ & Reintubation \\
\hline
\end{tabular}

${ }^{*}$ Total extubations; ${ }^{\circ} \mathrm{NR}$ : not reported; ${ }^{*} \mathrm{NoS}$ : without stridor; $\$$ S: with stridor; ${ }^{\$}$ Numbers represent the mean $\pm 1 \mathrm{SD}$. ICU, intensive care unit; MICU, medical intensive care unit; SICU, surgical intensive care unit. 
tribution. Other exclusion criteria listed in the primary articles included patients with airway abnormalities, hemodynamic instability, and failure to meet weaning criteria, but these were not uniformly applied. The length of mechanical ventilation ranged from $24 \mathrm{~h}$ to longer than 28 days. The quality scores based on the MINORS scoring system ranged from 8 to 14 with a maximum of 16 for observational studies. Five studies had scores of 12 or more. All the studies clearly stated the research question and had clinically relevant study goals for the patient population. All the patients met the inclusion criteria, which in general included all patients with planned extubation. All the studies collected the information prospectively and followed the protocol established at the beginning of the study (Table 2).

\section{Data synthesis}

These six studies reported results from 958 patients and 970 extubations. Eighty-two patients (8.5\%) had stridor postextubation, and the incidence of stridor ranged from $4.3 \%$ to $18 \%$ in these six studies (Table 3). The diagnosis of stridor depended on bedside criteria. Two studies reported the management of stridor. The weighted mean cuff leak volume was $119( \pm 51)$ mls in patients with stridor $(\mathrm{n}=82)$ and $313( \pm 24) \mathrm{mls}$ in patients without stridor $(\mathrm{n}=876) \quad(\mathrm{P}<0.01) \quad($ Table 3$)$. The weighted mean cuff leak expressed as a percent of tidal volume was $19.7( \pm 11.4) \%$ in patients with stri- dor; the weighted mean cuff leak percent was $53.7( \pm 8.8) \%$ in patients without stridor $(\mathrm{P}<0.01)$. A positive cuff leak test had a sensitivity of $0.61\left(95 \% \mathrm{CI}=0.49-0.73, \mathrm{I}^{2}=0.0 \%, \mathrm{P}=0.42\right)$ and a specificity of $0.88(95 \% \mathrm{CI}=0.86-0.90$, $\left.\mathrm{I}^{2}=89.5 \%, \mathrm{P}<0.01\right)$ in identifying patients with stridor. Forty-four patients (53.7\%) with stridor required reintubation (Table 4 ). The presence of stridor had a sensitivity of $0.60(95 \% \mathrm{CI}=0.48$ $\left.0.72, \mathrm{I}^{2}=82.5 \%, \mathrm{P}<0.01\right)$ and a specificity of 0.96 (95\% CI=0.94-0.97, $\left.\mathrm{I}^{2}=35.9 \%, \mathrm{P}=0.17\right)$ in identifying patients who needed reintubation (Table 5). Sixty-six patients (independent of the stridor outcome) required reintubation (Table 4). A positive cuff leak test had a sensitivity of 0.53 (95\% $\left.\mathrm{Cl}=0.39-0.66, \mathrm{I}^{2}=74.3 \%, \mathrm{P}<0.01\right)$ and $\mathrm{a}$ specificity of $0.86\left(95 \% \mathrm{CI}=0.84-0.89, \mathrm{I}^{2}=88.6 \%\right.$,

Table 2. MINORS criteria.

\begin{tabular}{|c|c|c|c|c|c|c|c|c|c|}
\hline Study & Aims & Inclusion & $\begin{array}{l}\text { Prospective } \\
\text { collection }\end{array}$ & Endpoints & $\begin{array}{c}\text { Unbiased } \\
\text { assessment }\end{array}$ & $\begin{array}{l}\text { Follow-up } \\
\text { period }\end{array}$ & $\begin{array}{l}\text { Loss to } \\
\text { follow-up }\end{array}$ & Power & Total \\
\hline Miller $^{2}$ & 2 & 2 & 2 & 2 & 2 & 2 & 2 & 0 & 14 \\
\hline Jaber $^{4}$ & 2 & 2 & 2 & 2 & 2 & 2 & 2 & 0 & 14 \\
\hline Sandhu ${ }^{5}$ & 2 & 2 & 2 & 2 & 0 & 0 & 0 & 0 & 8 \\
\hline Kriner ${ }^{7}$ & 2 & 2 & 2 & 2 & 2 & 2 & 2 & 0 & 14 \\
\hline Wang $^{9}$ & 2 & 2 & 2 & 2 & 2 & 2 & 2 & 0 & 14 \\
\hline DeBast $^{10}$ & 2 & 2 & 2 & 2 & 0 & 2 & 2 & 0 & 12 \\
\hline
\end{tabular}

MINORS, Methodological index for non-randomized studies.

Table 3. Stridor incidence.

\begin{tabular}{|c|c|c|c|c|c|}
\hline $\begin{array}{l}\text { Study } \\
\text { (ref) }\end{array}$ & $\begin{array}{l}\text { Patients/ } \\
\text { extubations }\end{array}$ & $\begin{array}{c}\text { Patients } \\
\text { stridor (incidence) }\end{array}$ & $\begin{array}{l}\text { CLV(mL) - CLV\% } \\
\text { stridor }\end{array}$ & $\begin{array}{l}\text { CLV(mL) - CLV\% } \\
\text { no stridor }\end{array}$ & $\begin{array}{l}{ }^{\circ} \text { CLV - CLV\% } \\
\text { cut-off }\end{array}$ \\
\hline Miller $^{2}$ & $88 / 100$ & $6(6 \%)$ & $\begin{array}{c}180 \pm 157 \mathrm{~mL} \\
--\end{array}$ & $\begin{array}{c}360 \pm 157 \mathrm{~mL} \\
--\end{array}$ & $\begin{array}{c}<110 \mathrm{~mL} \\
--\end{array}$ \\
\hline Jaber $^{4}$ & 112 & $13(12 \%)$ & $\begin{array}{c}59 \pm 92 \mathrm{~mL} \\
9 \pm 13 \%\end{array}$ & $\begin{array}{c}372 \pm 170 \mathrm{~mL} \\
56 \pm 20 \%\end{array}$ & $\begin{array}{c}<130 \mathrm{~mL} \\
12 \% \mathrm{TV}\end{array}$ \\
\hline Sandhu $^{5}$ & 110 & $13(11.8 \%)$ & $\begin{array}{c}63 \pm 74 \mathrm{~mL} \\
9 \pm 10 \%\end{array}$ & $\begin{array}{c}408 \pm 201 \mathrm{~mL} \\
57 \pm 24 \%\end{array}$ & $<10 \%$ TV \\
\hline Kriner $^{7}$ & 462 & $20(4.3 \%)$ & $\begin{array}{c}148 \pm 143 \mathrm{~mL} \\
30 \pm 27 \%\end{array}$ & $\begin{array}{c}277 \pm 149 \mathrm{~mL} \\
55 \pm 26 \%\end{array}$ & $\begin{array}{l}<110 \mathrm{~mL} \\
15.5 \% \mathrm{TV}\end{array}$ \\
\hline Wang $^{9}$ & 110 & $20(18 \%)$ & $\begin{array}{c}147 \pm 159 \mathrm{~mL} \\
29 \pm 31 \%\end{array}$ & $\begin{array}{c}271 \pm 148 \mathrm{~mL} \\
52 \pm 27 \%\end{array}$ & $<-\overline{-}$ \\
\hline De Bast ${ }^{10}$ & 76 & $10(13 \%)$ & $\begin{array}{c}44-50 \mathrm{~mL} \\
9.4 \% \mathrm{TV}\end{array}$ & $\begin{array}{c}232-249 \mathrm{~mL} \\
33.5 \% \mathrm{TV}\end{array}$ & $\begin{array}{c}-- \\
<15.5 \% \mathrm{TV}\end{array}$ \\
\hline
\end{tabular}

"CLV-cuff leak volume in mls, numbers represent the mean $\pm 1 \mathrm{SD}$; CLV\%- cuff leak volume expressed as percent of tidal volume, numbers represent the mean $\pm 1 \mathrm{SD}$; ${ }^{\circ}$ Optimal value from authors.

Table 4. Reintubation incidence.

\begin{tabular}{|c|c|c|c|c|c|c|c|}
\hline $\begin{array}{l}\text { Study } \\
\text { (ref) }\end{array}$ & $\begin{array}{l}\text { Patients/ } \\
\text { extubations }\end{array}$ & $\begin{array}{l}\text { Reintubation } \\
\text { all causes }\end{array}$ & $\begin{array}{l}\text { Reintubation } \\
\text { if PES }(+)\end{array}$ & \multicolumn{4}{|c|}{$\begin{array}{l}\text { Cuff leak test sensitivity } \\
\text { and specificity to predict reintubation }\end{array}$} \\
\hline Miller $^{2}$ & $88 / 100$ & $17 \%(17 / 100)$ & $50 \%(3 / 6)$ & $67 \%$ & $99 \%$ & $80 \%$ & $98 \%$ \\
\hline Jaber $^{4}$ & 112 & $9.8 \%(11 / 112)$ & $69 \%(9 / 13)$ & $81 \%$ & $96 \%$ & $69 \%$ & $97 \%$ \\
\hline Sandhu ${ }^{5}$ & 110 & $5.5 \%(6 / 110)$ & $46 \%(6 / 13)$ & $50 \%$ & $93 \%$ & $30 \%$ & $97 \%$ \\
\hline Kriner ${ }^{7}$ & 462 & $1.5 \%(7 / 462)$ & $35 \%(7 / 20)$ & $50 \%$ & $84 \%$ & $12 \%$ & $97 \%$ \\
\hline Wang $^{9}$ & 110 & $10 \%(11 / 110)$ & $55 \%(11 / 20)$ & $72 \%$ & $100 \%$ & $47 \%$ & $96 \%$ \\
\hline De Bast ${ }^{10}$ & 76 & $18.4 \%(14 / 76)$ & $11 \%(8 / 10)$ & $75 \%$ & $72 \%$ & $25 \%$ & $96 \%$ \\
\hline
\end{tabular}

PES, postextubation stridor; PPV, positive predictive values; NPV, negative predictive values. 
$\mathrm{P}<0.01$ ) for detecting patients requiring reintubation. These results indicate that the cuff leak test has a higher specificity than sensitivity, and the $\mathrm{I}^{2}$ tests indicate that there is significant heterogeneity among these studies. The cut-off value for an abnormal (positive) cuff leak test calculated by the authors of these studies ranged from $88 \mathrm{mls}$ to $140 \mathrm{mls}$ or $10 \%$ to $15.5 \%$ of the tidal volume (Table 3 ).

\section{Publication bias}

We did a regression analysis of the number of patients in each study against the diagnostic odds ratio for each study calculated by the Meta-DiSc software to identify possible publication bias. This analysis did not suggest any publication bias was present, but studies with fewer than 10 articles have a low power to detect publication bias. ${ }^{20}$

\section{Clinical details}

Clinical factors associated with stridor detailed in the results section of these articles included prolonged mechanical ventilation, a large endotracheal tube compared to tracheal size, female gender, difficult intubations, and self extubation (Table 6). However, the only association consistently identified in the studies was the cuff leak. Several studies did not identify prolonged intubation or female gender as risk factors for PES, and only one study used multivariate analysis. Wang, et al. reported that corticosteroids increased the cuff leak in patients who had PES and required reintubation. ${ }^{9}$

\section{Discussion}

Our literature review identified six papers, which evaluated the utility of quantitative cuff leak measurements for predicting either postextubation stridor or the need for reintubation in adult patients with acute respiratory failure in ICUs. ${ }^{2,4,5,7,9,10}$ These studies included 958 patients in observational cohorts; $6.9 \%$ of these patients required reintubation and $8.5 \%$ had postextubation stridor. The presence of stridor postextubation had a positive likelihood ratio of 13.4 (95\% confidence interval 6.9 to 25.7) for predicting reintubation; the absence of stridor had a negative likelihood ratio of 0.3 (95\% confidence interval 0.1 to 0.9 ) for predicting reintubation. These likelihood ratios provide very useful information to the clinician in the ICU. If $6.9 \%$ of patients in this cohort with acute respiratory failure needs reintubation, and the likelihood ratio for a positive cuff leak test predicting stridor is 6.8 , and the likelihood ratio for stridor predicting reintubation is 13.4, then the patient who has a positive cuff leak test and then develops stridor will have an $87 \%$ probability of needing reintubation $[(6.9 \% / 93.1 \%)(6.8)(13.4)=6.7$ or $87 \%$, assuming independent probabilities]. Conversely, a patient with a negative cuff leak test and no stridor has a probability of $1 \%$ of needing reintubation.

Two recent studies concluded that cuff leak tests do not predict postextubation stridor or successful extubation. Sukhupanyarak reported results in 543 patients in intensive care units and found that an absent leak did not predict stridor. ${ }^{13}$ Cuff leak was detected by auscultation by ICU nurses in this study. Shin, et $a l$. reported that the cuff leak test did not predict reintubation in a study involving critically ill trauma patients. ${ }^{14}$ However, the four patients (4/49) requiring reintubation in this study were reintubated four or more hours after extubation for increasing respiratory failure. These differences in outcome likely reflect the study design and the differences in patient populations and study endpoints. The studies we reviewed depended on observational cohorts of relatively small patient populations. They included different numbers of patients and patients from different types of ICUs who required mechanical ventilation for varying periods (1 to more than 28 days). Consequently, these patient cohorts were heterogeneous. In addition, these studies did not use a double blind randomized protocol, and there was no reference standard. There was no blinding or allocation concealment, and the possibility of bias is present, given the main outcome in most studies was stridor identified at the bedside using clinical criteria. It is also possible that some patients with significant upper airway narrowing do not have stridor if their respiratory effort is weak and they cannot generate adequate airflow. The clinical implication of stridor depends on whether or not the patient has respiratory distress associated

Table 5. Utility of the cuff leak test in intensive unit care patients.

\begin{tabular}{|c|c|c|c|c|}
\hline & Sensitivity & Specificity & $\operatorname{LR}(+)^{\circ}$ & $\operatorname{LR}(-)^{c}$ \\
\hline Low cuff leak test result predicts stridor & $\begin{array}{c}0.61 \\
(0.49-0.73)^{*} \\
\mathrm{I}^{2}=0.0 \%, \mathrm{P}=0.42\end{array}$ & $\begin{array}{c}0.88 \\
(0.86-0.90) \\
\mathrm{I}^{2}=89.5 \%, \mathrm{P}<0.01\end{array}$ & $\begin{array}{c}6.8 \\
(3.3-13.9) \\
\mathrm{I}^{2}=78.2 \%, \mathrm{P}<0.01\end{array}$ & $\begin{array}{c}0.5 \\
(0.4-0.7) \\
I^{2}=0.0 \%, P=0.42\end{array}$ \\
\hline Low cuff test result predicts reintubation & $\begin{array}{c}0.53 \\
(0.39-0.66) \\
I^{2}=74.3 \%, P<0.01\end{array}$ & $\begin{array}{c}0.86 \\
(0.84-0.89) \\
\mathrm{I}^{2}=88.6 \%, \mathrm{P}<0.01\end{array}$ & $\begin{array}{c}5.5 \\
(2.7-11.1) \\
I^{2}=71.1 \%, P=0.52\end{array}$ & $\begin{array}{c}0.5 \\
(0.2-1.1) \\
I^{2}=87.0 \%, P<0.01\end{array}$ \\
\hline Stridor predicts reintubation & $\begin{array}{c}0.60 \\
(0.48-0.72) \\
I^{2}=82.5 \%, P<0.01\end{array}$ & $\begin{array}{c}0.96 \\
(0.94-0.97) \\
\mathrm{I}^{2}=35.9 \%, \mathrm{P}=0.17\end{array}$ & $\begin{array}{c}13.4 \\
(6.9-25.7) \\
I^{2}=70.2 \%, P<0.01\end{array}$ & $\begin{array}{c}0.3 \\
(0.1-0.9) \\
I^{2}=89.2 \%, P<0.01\end{array}$ \\
\hline
\end{tabular}

"95\% confidence interval; ${ }^{\circ}$ LR (+), LR (-): positive and negative likelihood ratio. Calculated from ref. $1,3,4,6,8,9$.

Table 6. Factors associated with cuff leak.

\begin{tabular}{|c|c|c|c|}
\hline Study & Factors associated with stridor & Factors not associated with stridor & Analysis \\
\hline Miller ${ }^{2}$ & Cuff leak & ETT size, days intubated \# intubations & Logistic regression \\
\hline Jaber $^{4}$ & $\begin{array}{l}\text { Cuff leak, female gender, SAPS score } \\
\text { traumatic intubation, days intubated } \\
\text { prior self-extubation }\end{array}$ & ETT size & Univariate \\
\hline Sandhu $^{5}$ & Cuff leak, days intubated & ETT size, overall injury score & Univariate \\
\hline Kriner ${ }^{7}$ & Cuff leak, female gender, days intubated & Age & Univariate \\
\hline Wang $^{9}$ & Cuff leak, female gender & Age, days intubated, prior intubation & Univariate \\
\hline DeBast $^{10}$ & Cuff leak & None reported & Univariate \\
\hline
\end{tabular}

ETT, endotracheal tube; SAPS, simplified acute physiology score. 
with it, whether the patient responds to medical therapy, and whether the patient ultimately requires reintubation. In addition, the cuff leak test will not identify patients with inadequate resolution of their underlying disease who have persistent respiratory distress postextubation and then require reintubation. Although quantitative cuff leak measurements are relatively simple measurements, they do require attention to details, especially removal of secretions in the hypopharyngeal area and the ETT. Respiratory system mechanics also can influence the result if high resistance or low compliance increases volume loss during the delivery of the tidal volume. However, this result requires an open airway around the ETT and potentially has the same significance as a leak during exhalation. ${ }^{21}$ Respiratory effort during the inspiratory phase of the tidal volume may increase the total tidal volume if air is entrained around the ETT during inspiration. This would potentially overestimate the fraction exhaled around the ETT. These variables increase the heterogeneity among these cuff leak studies. Ochoa and coworkers recently published a meta-analysis of studies and concluded that although there was significant statistical heterogeneity in these studies, a cuff leak test with no leak should alert the clinician to the possibility of upper airway obstruction.22 This analysis included patients immediately post surgery and studies using qualitative leak tests. We limited our review to studies of patients with acute respiratory failure requiring mechanical ventilation who had quantitative cuff leak measurements but also found significant heterogeneity in the studies. However, we think these patients are representative of most patients managed in surgical or medical ICUs.

In summary, studies in patients with acute respiratory failure in ICUs demonstrate that low cuff leak volumes or fractions of tidal volume do identify patients with upper airway narrowing, most likely secondary to laryngeal edema related to endotracheal intubation. These patients with low volumes are more likely to have stridor and to require reintubation. Patients with normal leak volumes are less likely to have stridor and to require reintubation. A low cuff leak volume should be communicated to clinicians to review whether extubation is safe and to decide whether or not there are therapeutic options available to increase extubation safety. None of the studies reported to date has used a randomized control design in which clinicians responsible for extubation were either given or not given information about the cuff leak. Any study with this design would require a large number of patients, given the low event rates, and would require multiple ICUs. Wittekamp and coworkers recently outlined a strategy using patient assessment for risk factors for upper airway obstruction and cuff leak tests. They suggest that patients with risk factors (such as female gender and large ETT) and no leak should be given methylprednisolone for $12 \mathrm{~h}$ before extubation and should be extubated with an airway catheter in place. ${ }^{23}$ Francois has reported that pretreatment with methylprednisolone prevents postextubation laryngeal edema and demonstrated that information on cuff leak could lead to therapeutic interventions. ${ }^{24}$ Based on our analysis of studies relevant to ICU physicians, we conclude that cuff leak tests provide important information and that volumes below $20 \%$ of the tidal volume represent a concern to the respiratory care team.

\section{References}

1. MacIntyre NR, Cook DJ, Ely EW Jr, et al. Evidence-based guidelines for weaning and discontinuing ventilatory support: a collective task force facilitated by the American College of Chest Physicians; the American Association for Respiratory Care; and the American College of Critical Care Medicine. Chest 2001;120 Suppl 6: 375S-95S.

2. Miller RL, Cole RP. Association between reduced cuff leak volume and postextubation stridor. Chest 1996;110:1035-40.

3. Maury E, Guglielminotti J, Alzieu M, et al. How to identify patients with no risk for postextubation stridor? J Crit Care 2004; 19:23-8.

4. Jaber S, Chanques G, Matecki S, et al. Post-extubation stridor in intensive care unit patients: Risk factors evaluation and importance of the cuff-leak test. Intensive Care Med 2003;29:69-74.

5. Sandhu RS, Pasquale MD, Miller K, Wasser TE. Measurement of endotracheal tub cuff leak to predict postextubation stridor and need for reintubation. J Am Coll Surg 2000;190:682-7.

6. Fisher MM, Raper RF. The cuff leak test for extubation. Anaesthesia 1992;47:10-2.

7. Kriner EJ, Shafazand S, Colice GL. The endotracheal tube cuff-leak test as a predictor for postextubation stridor. Respir Care 2005:50:1632-8.

8. Engoren M. Evaluation of the cuff-leak test in a cardiac surgery population. Chest 1999;116:1029-31.

9. Wang CL, Tsai, Huang CC, et al. The role of the cuff leak lest in predicting the effects of corticosteroid treatment on postextubation stridor. Chang Gung Med J 2007;30: 53-61.

10. De Bast YD, Backer DD, Moraine JJ, et al. The cuff leak test to predict failure of tracheal extubation for laryngeal edema.
Intensive Care Med 2002;28:1267-72.

11. Chung YH, Chao TY, Chiu CT, Lin MC. The cuff-leak test is a simple tool to verify severe laryngeal edema in patients undergoing long-term mechanical ventilation. Crit Care Med 2006;34:409-14.

12. Adderley RJ, Mullins GC. When to extubate the croup patient: the "leak" test. Can J Anaesth 1987;34:304-6.

13. Sukhupanyarak S. Risk factors evaluation and the cuff leak test as predictors for postextubation stridor. J Med Assoc Thai 2008;91:648-53.

14. Shin SH, Heath K, Reed S, et al. The cuff leak test is not predictive of successful extubation. Am Surg 2008;74:1182-5.

15. Slim K, Nini E, Forestier D, et al. Methodological index for non-randomized studies (minors): development and validation of a new instrument. ANZ J Surg 2003;73:712-6.

16. Meade MO, Richardson S. Selecting and appraising studies for a systematic review. Ann Intern Med 1997;127:531-7.

17. Harris RP, Helfand M, Woolf SH, et al. Current methods of the US preventive services task force: a review of the process. Am J Prev Med 2001;20 Suppl 3:21-35.

18. The Cochrane Collaboration. The Cochrane Manual Issue 1, 2008, section 2.2.5.4 Cochrane Library Feedback House Rules [updated 15 November 2007]. Available from: http://www.cochrane.org/ admin/manual.htm

19. Zamora J, Abraira V, Muriel A, et al. MetaDiSc: a software for meta-analysis of test accuracy data. BMC Med Res Methodol 2006;6:31.

20. Deeks JJ, Masaskill P, Irwig L. The performance of tests of publication bias and other sample size effects in systematic reviews of diagnostic accuracy was assessed. J Clin Epidemiol 2005;58:882-93.

21. Prinianakis G, Alexopoulou C, Mamidakis E, et al. Determinants of the cuff-leak test: a physiological study. Crit Care 2005;9: R24-31.

22. Ochoa ME, Marin Mdel C, Frutos-Vivar F, et al. Cuff-leak test for the diagnosis of upper airway obstruction in adults: a systematic review and meta-analysis. Intensive Care Med 2009;35:1171-9.

23. Wittekamp BH, van Mook WN, Tjan DH, et al. Clinical review: post-extubation laryngeal edema and extubation failure in critically ill adult patients. Crit Care 2009; 13:233.

24. Francois B, Bellissant E, Gissot V, et al. 12$\mathrm{h}$ pretreatment with methylprednisolone versus placebo for prevention of post-extubation laryngeal oedema: a randomized double-blind trial. Lancet 2007;369:1083-9. 